\title{
Associated microsatellite alterations in mitochondrial DNA and in TP53 in thoracic esophageal squamous cell carcinoma
}

\author{
CHEN-SUNG LIN ${ }^{1,2,8}$, LIANG-SHUN WANG ${ }^{2,7,13}$, SHI-CHUAN CHANG ${ }^{2,3,11}$, \\ TEH-YING CHOU ${ }^{2,12}$, WEN-HU HSU ${ }^{1,10}$, CHIN-SAN LIU ${ }^{14}$, MAU-HWA LEE ${ }^{9}$, \\ MING-YI CHUNG ${ }^{5,15^{*}}$ and YAU-HUEI WEI ${ }^{2,4,6^{*}}$
}

\begin{abstract}
${ }^{1}$ Department of Medicine, ${ }^{2}$ Institute of Clinical Medicine, ${ }^{3}$ Institute of Emergency and Critical Care Medicine, School of Medicine, ${ }^{4}$ Department of Biochemistry and Molecular Biology, and ${ }^{5}$ Department of Life Sciences and Institute of Genome Sciences, School of Life Sciences, National Yang-Ming University, Taipei 112; ${ }^{6}$ Department of Medicine, Mackay Medical College, New Taipei City 252; ${ }^{7}$ Graduate Institute of Clinical Medicine, Taipei Medical University, Taipei 110; ${ }^{8}$ Division of Thoracic Surgery, Department of Surgery, ${ }^{9}$ Division of Gastroenterology, Department of Internal Medicine, Taipei Hospital, Department of Health, The Executive Yuan, New Taipei City 242; ${ }^{10}$ Division of Thoracic Surgery, Department of Surgery, ${ }^{11}$ Division of General Chest Medicine, Department of Chest, ${ }^{12}$ Division of Surgical Pathology, Department of Pathology and Laboratory Medicine, Taipei Veterans General Hospital, Taipei 112; ${ }^{13}$ Division of Thoracic

Surgery, Department of Surgery, Taipei Medical University-Shuang Ho Hospital, New Taipei City 235;

${ }^{14}$ Department of Neurology and Vascular and Genomic Center, Changhua Christian Hospital, Changhua 500;

${ }^{15}$ Department of Medical Research and Education, Taipei Veterans General Hospital, Taipei 112, Taiwan, R.O.C.
\end{abstract}

Received December 22, 2011; Accepted February 7, 2012

DOI: 10.3892/or.2012.1761

\begin{abstract}
We investigated the microsatellite alterations in mitochondrial DNA (mtDNA) and in TP53 in thoracic esophageal squamous cell carcinomas (TESCC). Using laser microdissection, 66 paired non-cancerous esophageal muscles, non-cancerous esophageal mucosa, cancerous TESCC nests plus 35 metastatic lymph nodes harvested from 66 resected esophagi of TESCC patients were subjected to DNA extraction. D310 and D17S960 were chosen as markers to address
\end{abstract}

Correspondence to: Dr Yau-Huei Wei, Department of Biochemistry and Molecular Biology, School of Life Sciences, National Yang-Ming University, Taipei 112, Taiwan, R.O.C.

E-mail: joeman@ym.edu.tw

Dr Ming-Yi Chung, Department of Life Sciences and Institute of Genome Sciences, School of Life Sciences, National Yang-Ming University, Taipei 112, Taiwan, R.O.C.

E-mail: mychung@vghtpe.gov.tw

*Contributed equally

Abbreviations: LOH, loss of heterozygosity; MI, microsatellite instability; mtDNA, mitochondrial DNA; nDNA, nuclear DNA; PCR, polymerase chain reaction; TESCC, thoracic esophageal squamous cell carcinoma

Key words: heteroplasmy, loss of heterozygosity, microsatellite instability, mitochondrial DNA, TP53 gene, thoracic esophageal squamous cell carcinoma microsatellite alterations in mtDNA, including changes in copy number and homoplasmic/heteroplasmic mutations of mtDNA, and in TP53, including loss of heterozygosity (LOH) and microsatellite instability (MI). From non-cancerous esophageal mucosa to cancerous TESCC nests and then metastatic lymph nodes, a trend of homoplasmic D310 mutation $(10.6,25.8,31.4 \%$; $\mathrm{P}=0.023)$, an ever increase of mtDNA copy ratios $(0.892,1.128,1.183 ; \mathrm{P}=0.018)$ and an elevated incidence of TP53 LOH $(19.7,34.8,37.1 \%$; $\mathrm{P}=0.010)$ were observed. From T1, T2, T3 to T4 TESCC, the incidence of TP53 LOH $(12.5,16.7,34.8,52.2 \%$; $\mathrm{P}=0.011)$ was increased, in a stepwise fashion. Furthermore, we observed an association of TP53 LOH with an increased mtDNA copy ratio $(\mathrm{P}=0.022)$ and TP53 MI with heteroplasmic D310 mutation $(\mathrm{P}=0.069)$ in TESCC. Concurrent and associated microsatellite alterations in mtDNA and in TP53 in TESCC support the cancer clonal expansion theory and imply a possible relationship between the mitochondria and p53 in TESCC.

\section{Introduction}

Thoracic esophageal squamous cell carcinoma (TESCC) is an aggressive neoplasm in Asian countries, including Taiwan (1-5). Although the alterations in mitochondrial DNA (mtDNA) at the D-loop or in nuclear DNA (nDNA) at TP53 have been studied in TESCC with clinical significance (6-8), few appraised them and discussed their associations concurrently, except some reports in colon and breast cancers $(9,10)$. Thus, this study was designed to evaluate the genetic alterations in mtDNA and in TP53 and appraise their associations in TESCC. 
Human mtDNA is a $16569 \mathrm{bp}$, double-stranded and closed circular DNA molecule. Generally, each human cell contains several hundreds to one thousand of mitochondria and each mitochondrion harbors 2-10 copies of mtDNA $(11,12)$. Human mtDNA is transmitted through the maternal lineage with a single origin. As a result, the mtDNA in the post-mitotic tissues at birth are assumed identical, and such a feature is referred to as a homoplasmy/homoplasmic distribution. Nuclear DNA (nDNA), on the other hand, is inherited from both parents equally, i.e., half from mother and the other half from father, and such a feature is referred to as heterozygosity. Any perturbations to the heterozygosity of nDNA or the homoplasmy of mtDNA denote the possibility of DNA alterations. Several biological methods have been developed to detect these perturbations, and the analysis of microsatellite alterations close to a specific target gene on nDNA or on mtDNA was commonly advocated (13).

Microsatellites are tandem repeats of short DNA motifs that contains 1-6 nucleotides scattered in the genomic DNA. The number of the short tandem repeats may be variable in a population or different in an individual if harboring heterozygous alleles. These characteristics render them a hot spot for mutational analysis. Microsatellite analysis is a polymerase chain reaction (PCR)-based technique that permits the detection of cancer-specific mutations in nDNA, including the loss of heterozygosity $(\mathrm{LOH}$, which denotes the quantitative alterations of DNA copy number between heterozygous alleles) or microsatellite instability (MI, which denotes the formation of a new shifted allele) or in mtDNA, including the change of the copy number or heteroplasmic/homoplasmic mutations, respectively (13). Quantitatively, both $\mathrm{LOH}$ in nDNA and the change of copy number in mtDNA suggest the quantitative changes of genomic DNA. Qualitatively, both MI in nDNA and heteroplasmic/homoplasmic mutation in mtDNA suggest the formation of new shifted DNA. Microsatellite markers, including mononucleotide poly-C repeats on mtDNA (e.g., D310) or dinucleotide CA repeat on nDNA close to TP53 (e.g., D17S960) have been analyzed in TESCC, however, their roles and associations in TESCC have remained obscure $(6,14-16)$.

In this study, we performed the microsatellite analysis to identify genomic alterations in mtDNA and in nDNA (TP53) in TESCC and evaluated their associations among a set of 66 paired TESCC clinical samples. We believe that the findings are useful for us to gain a better understanding of the pathophysiology of TESCC from the viewpoint of microsatellite alterations in mtDNA and TP53.

\section{Materials and methods}

TESCC patient collection, tissue preparation and DNA extraction. A total of 66 TESCC patients underwent surgical resection without pre-operative neoadjuvant therapies between January 2000 and December 2003 at Taipei Veterans General Hospital were enrolled for analysis (2). Approval from the Institutional Review Board of Taipei Veterans General Hospital was obtained to conduct this retrospective study. Using laser microdissection, 233 samples dissected from the 66 resected esophagi, including 66 paired non-cancerous esophageal muscles $(n=66)$, non-cancerous esophageal mucosa $(n=66)$ and cancerous TESCC nests $(n=66)$ along with 35 metastatic lymph nodes retrieved from 41 nodal positive patients, were subjected to DNA extraction as previously described (17). The DNA samples were stored at $-20^{\circ} \mathrm{C}$ until use.

Microsatellite marker for mtDNA analysis. The microsatellite marker D310 was adopted for mtDNA analysis. This marker is located at the D-loop of mtDNA, about $250 \mathrm{bp}$ from the coding region of mtDNA, and harbors variable 6-9 poly-C repeats before nucleotide position 310 of mtDNA. Its clinical significance has been reported in gastric, pulmonary and breast cancers (18-20). Based on our previous study, the copy number and D310 mutation of mtDNA in TESCC were determined by quantitative real-time PCR and direct sequencing, respectively (17,21).

The mtDNA copy number was determined by quantitative real-time PCR, by amplification of $1 \mu \mathrm{l}$ of sample DNA in a $10 \mu \mathrm{l}$ reaction mixture containing $0.25 \mu \mathrm{l}$ of each primer $(20 \mu \mathrm{M}), 1.2 \mu \mathrm{l}$ of $3 \mathrm{mM} \mathrm{MgCl} \mathrm{M}_{2}, 1 \mu \mathrm{l}$ of LightCycler SYBRGreen mixed reagent (Roche Applied Science, Mannheim, Germany), and $6.3 \mu \mathrm{l}$ of PCR grade $\mathrm{H}_{2} \mathrm{O}$. Also amplified were DNA samples from 143B cells $(1.25 \mathrm{ng} / \mu \mathrm{l})$ and PCR grade $\mathrm{H}_{2} \mathrm{O}$, as the positive and negative controls, respectively. The PCR was performed as follows: hot start at $95^{\circ} \mathrm{C}$ for $10 \mathrm{~min}$ followed by 40 cycles of $95^{\circ} \mathrm{C}$ for $20 \mathrm{sec}, 62^{\circ} \mathrm{C}$ for $20 \mathrm{sec}$ and $72^{\circ} \mathrm{C}$ for $20 \mathrm{sec}$. Fluorescence intensity was measured at the end of each extension phase at $72^{\circ} \mathrm{C}$. The sequences of the primers used for the amplification of mtDNA (ND1 region) were mtF3212, 5'-CACCCAAGAACAGGGTTTGT-3' and mtR3319, 5'-TGGCCATGGGATTGTTGTTAA-3'. The sequences of primers used for the amplification of nDNA (18S rRNA region) were 18S1546F 5'-TAGAGGGACAAGTG GCGTTC-3' and 18S1650R 5'-CGCTGAGCCAGTCAGT GT-3' (22). Standard curves representing the amounts of both mtDNA and nDNA related to amplification threshold cycles $(\mathrm{Ct})$ were established by using the cellular DNA of 143B osteosarcoma cells $\left(\mathrm{R}^{2}=0.9973\right.$ for $\mathrm{mtDNA}$ and $\mathrm{R}^{2}=0.9973$ for nDNA) as previously described (17). All the Ct values of the analyzed samples were titrated within the linear range of our standard curves. For each sample, the $\mathrm{Ct}$ values for mtDNA and nDNA were determined, and the amounts of mtDNA and nDNA relative to those of $143 \mathrm{~B}$ cells were calculated and normalized by standard curves. The mtDNA copy number (mtDNA/nDNA) of the 143B cell line was used as the internal standard and was defined as 1 . The relative mtDNA copy numbers of the clinical samples were then determined accordingly. Each analysis was performed in duplicate and the mean value was used for data presentation. Furthermore, we defined the mtDNA copy ratio as the mtDNA copy number of noncancerous esophageal mucosa, cancerous TESCC nest and metastatic lymph node divided by that of paired non-cancerous esophageal muscle for comparisons.

The D310 microsatellite instability was assessed by PCR amplification followed by direct sequencing. Each PCR reaction contained $25 \mu \mathrm{l}$ of AmpliTaq Gold PCR Master mix (Applied Biosystems, Foster City, CA), $22 \mu \mathrm{l}$ of PCR grade $\mathrm{H}_{2} \mathrm{O}, 1 \mu \mathrm{l}$ of each primer (H76: 5'-CAAGCGATAGCATT GCGA-3' and L335: 5'-TAAGTGCTGTGGCCAGAAGC-3') $(20 \mu \mathrm{M})$ and $1 \mu \mathrm{l}$ of sample DNA (23). The PCR conditions were set as the following: $95^{\circ} \mathrm{C}$ for $5 \mathrm{~min}$ followed by 40 cycles of amplification at $95^{\circ} \mathrm{C}$ for $15 \mathrm{sec}, 58^{\circ} \mathrm{C}$ for $15 \mathrm{sec}$ and $72^{\circ} \mathrm{C}$ 

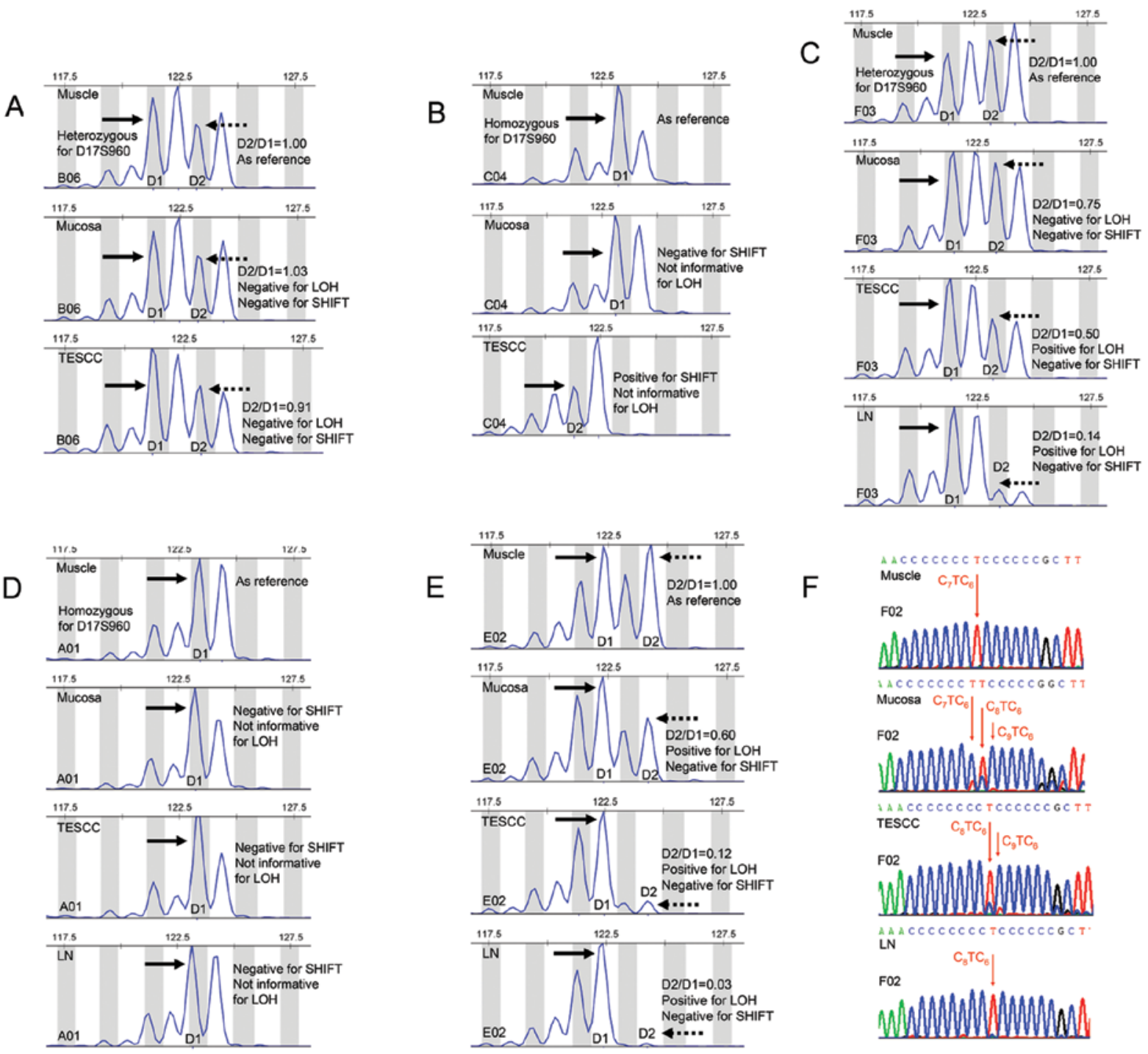

Figure 1. Illustrations are the representative data of microsatellite alterations in TP53 at D17S960 and in mtDNA at D310 of the D-loop region. Muscle, mucosa, TESCC, and LN are abbreviated for non-cancerous esophageal muscle, non-cancerous esophageal mucosa, cancerous TESCC nest, and metastatic lymph node in each TESCC patient, respectively. The scale on the y-axis represents the fluorescence intensity of the peaks for allelic DNA copy number and the X-axis shows the PCR product size in base pairs. (A) Patient B06 harbored a heterozygous allele (D1/D2) for D17S960. After normalizing with the allelic ratio (D2/D1) of the muscle (taken as 1.00), the relative allelic ratios of the mucosa and TESCC were calculated to be 1.03 and 0.91 , respectively. They were negative for both LOH and MI (MI was illustrated as SHIFT in this figure). (B) Patient C04 harbored a homozygous allele (D1/D1) for D17960 and the possibilities of LOH in the mucosa and TESCC were not informative. However, the size of the PCR product was shifted from D1 to D2 in the TESCC, and MI was detected. No MI was observed in the mucosa. (C) Patient F03 harbored a heterozygous allele (D1/D2) for D17S960. After normalizing with the allelic ratio (D2/D1) of the muscle (taken as 1.00), the relative allelic ratios of the mucosa, TESCC, and LN were $0.75,0.50(<0.65)$, and $0.14(<0.65)$, respectively. $\mathrm{LOH}$ were detected in the TESCC and LN, but not in mucosa. No MI was detected. (D) Patient A01 harbored a homozygous allele (D1/D1) for D17960 and the possibility of LOH in mucosa, TESCC, and LN are not informative. None of them harbored MI. (E) Patient E02 harbored a heterozygous pattern (D1/D2) for D17S960. After normalizing with the allelic ratio (D2/D1) of the muscle (taken as 1.00), the relative allelic ratios of the mucosa, TESCC, and LN were $0.60(<0.65), 0.12(<0.65)$, and $0.03(<0.65)$, respectively. LOH were detected in the mucosa, TESCC and LN. None of them harbored MI. (F) D310 alterations of patient F02 are illustrated. Homoplasmy with 7 monocytidine repeats $\left(\mathrm{C}_{7} \mathrm{TC}_{6}\right)$ was detected in the muscle and 8 monocytidine repeat $\left(\mathrm{C}_{8} \mathrm{TC}_{6}\right)$ in the $\mathrm{LN}$. Heteroplasmic mixtures of $\mathrm{C}_{8} \mathrm{TC}_{6}, \mathrm{C}_{7} \mathrm{TC}_{6} \mathrm{plus}_{9} \mathrm{C}_{9} \mathrm{TC}_{6}$ were detected in the mucosa, and $\mathrm{C}_{8} \mathrm{TC}_{6}$ and $\mathrm{C}_{9} \mathrm{TC}_{6}$ in the TESCC. As a result, mucosa, TESCC, and LN harbored a heteroplasmic, heteroplasmic, and homoplasmic D310 mutations, respectively, when compared to the $\mathrm{D} 310$ pattern of muscle. Furthermore, the homoplasmic $\mathrm{C}_{8} \mathrm{TC}_{6}$ alteration at $\mathrm{D} 310$ in the $\mathrm{LN}$ was also detected in the paired mucosa and TESCC samples.

for $30 \mathrm{sec}$, and the final extension at $72^{\circ} \mathrm{C}$ for $7 \mathrm{~min}$. In each run, $\mathrm{PCR}$ grade $\mathrm{H}_{2} \mathrm{O}$ and DNA from the 143B osteosarcoma cell line $(1.25 \mathrm{ng} / \mu \mathrm{l})$ instead of sample DNA were included as the negative and positive controls, respectively. PCR products were subjected to electrophoresis on a $3 \%$ agarose gel to confirm the band of interest and then subject to direct sequencing. Compared to the D310 sequence patterns in the paired non-cancerous esophageal muscle, any heteroplasmic/ homoplasmic shifting of the mono-nucleotide poly-C repeats in the non-cancerous esophageal mucosa, cancerous TESCC nest and metastatic lymph node were termed as heteroplasmic/ homoplasmic D310 mutation (Fig. 1F) (17).

Microsatellite marker for TP53 analysis. D17S960, a marker containing CA dinucleotide repeats located at 17p13.1 about 310-340 kb from TP53, was chosen for TP53 analysis (24). Its clinical implications have been reported in adrenocortical tumor, gastric cancer, bladder cancer and glioblastoma (25-28). 
Using PCR, D17S960 was amplified in a $40 \mu \mathrm{l}$ reaction mixture under initial denaturation at $95^{\circ} \mathrm{C}$ for $5 \mathrm{~min}, 45$ cycles of $95^{\circ} \mathrm{C}$ for $15 \mathrm{sec}, 58^{\circ} \mathrm{C}$ for $15 \mathrm{sec}$, and $72^{\circ} \mathrm{C}$ for $30 \mathrm{sec}$, and a final extension at $72^{\circ} \mathrm{C}$ for $60 \mathrm{~min}$ to minimize the effect of template-independent adenine addition. The sequences of primers used were D17S960F: 5'-TGATGCATATACATGCG TG-3' with fluorescent FAM labeled at its 5' end and D17S960R: 5'-TAGCGACTCTTCTGGCA-3' (24). A mixture containing $1 \mu \mathrm{l}$ of PCR product, $10 \mu \mathrm{l}$ of Hi-Di formaldehyde and $0.2 \mu \mathrm{l}$ of ROX $500 \mathrm{HD}$ size standard was denatured at $95^{\circ} \mathrm{C}$ for $5 \mathrm{~min}$ and then loaded onto an automated DNA sequencer for analysis (ABI Prism 3730 Genetic Analyzer, Applied Biosystems). Using GeneMapper software, version 3.7 (Applied Biosystems), the peak heights (y-axis) representing the DNA copy numbers of the alleles were measured to calculate an allelic ratio. Like the mtDNA copy ratio, the allelic ratios of non-cancerous mucosa, cancerous TESCC nest and metastatic lymph node were divided by that of paired non-cancerous esophageal muscle in each patient to get a relative allelic ratio. A relative allelic ratio below 0.65 or above $1.55(\sim 1 / 0.65)$ is considered as a positive result for $\mathrm{LOH}$ (29-31). Those without definite $\mathrm{LOH}$ were classified as negative when harboring heterozygous alleles or not informative in case of a homozygous individual (Fig. 1A, C and E). Similar to the heteroplasmic/homoplasmic D310 mutation in mtDNA, any newly formed DNA patterns detected in the non-cancerous mucosa, cancerous TESCC nest or metastatic lymph nodes, when compared to the allelic DNA sizes (X-axis) of paired non-cancerous esophageal muscle, were classified as MI. Those samples without documented MI were classified as negative (Fig. 1B and D).

Statistics. All the statistical analyses were performed using the SPSS 12.0 (Statistical Package for the Social Sciences, 12.0). The continuous variables were compared by using Student's t-test/Mann-Whitney U test between two groups or ANOVA/Kruskall-Wallis $\mathrm{H}$ test among three or more groups when appropriate. Categorical variables between groups were compared using the $\chi^{2}$ test, Fisher exact test, or $\chi^{2}$ test for trend when appropriate. Survival probability was calculated and differentiated by the log-rank test among different levels within each categorical variable. Possible prognostic factors associated with a significance level $<0.20$ were considered in a multivariable Cox's proportional hazard regression analysis. The difference between groups was considered significant when a $\mathrm{P}$-value $<0.05$.

\section{Results}

Demographic data and possible prognostic variables. From January 2000 to December 2003, a total of 66 TESCC patients ( 57 men) with a mean age of 61.3 years were recruited for analysis. Their mean and median survivals were 30.8 and 25.7 months, and the accumulative 1-, 2-, 3-, and 5-year survival rates were $67.6,51.9,34.0$ and $29.3 \%$, respectively. The demographic data and possible prognostic variables are summarized in Table I. According to the AJCC cancer stage system, the 7th edition, for esophageal squamous cell carcinoma, 9 patients $(13.6 \%)$ were in stage I, $17(25.8 \%)$ in stage II, $40(60.6 \%)$ in stage III, and $0(0 \%)$ in stage IV (Table I) (32), respectively.
Forty-four TESCC (66.7\%) harbored a D310 mutation in mtDNA, including $27(40.9 \%)$ heteroplasmic mutations and 17 (25.8\%) homoplasmic mutations (Fig. 1F, Table I). Positive TP53 LOH and MI at D17S960 were detected in 23 (34.8\%) and $6(9.1 \%)$ TESCC specimens, respectively (Fig. 1A-E, Table I).

In this cohort, $\mathrm{T}$ status $[\mathrm{P}=0.025$; hazard ratio $(\mathrm{HR})=1.524$, 95\% CI, 1.046-2.222], $\mathrm{N}$ status $(\mathrm{P}=0.001 ; \mathrm{HR}, 1.872,95 \% \mathrm{CI}$, 1.315-2.665) and D310 mutation ( $\mathrm{P}=0.097 ; \mathrm{HR}, 1.835,95 \% \mathrm{CI}$, 0.896-3.759) were identified as independent prognostic factors with elevated hazards to worse outcomes (Table I).

Microsatellite alterations in mtDNA among the analyzed tissues. Regarding the microsatellite alterations in mtDNA at D310 among the three groups of non-cancerous esophageal mucosa $(n=66)$, cancerous TESCC nests $(n=66)$ and metastatic lymph nodes $(\mathrm{n}=35)$, there were a trend of homoplasmic D310 mutation $(10.6,25.8,31.4 \%, \mathrm{P}=0.023)$ and an ever increase of mtDNA copy ratio $(0.892,1.128,1.183, \mathrm{P}=0.002)$.

Among the 35 analyzed nodal positive TESCC patients, 23 had D310 mutations in the metastatic lymph nodes (nodal D310 mutation TESCC patients, Table II), and $11(11 / 23$, 47.8\%) had homoplasmic D310 mutation. Nine (9/11, 81.8\%) of the 11 patients with homoplasmic D310 mutations exhibited a concurrent D310 mutation in the paired non-cancerous mucosa, cancerous TESCC nests and metastatic lymph nodes, and the D310 variant in the metastatic lymph node could also be detected in the paired non-cancerous mucosa and cancerous TESCC nests, like patient F02 (Fig. 1F).

Microsatellite alterations in TP53 among the analyzed tissues. Among the three groups of non-cancerous esophageal mucosa $(n=66)$, cancerous TESCC nests $(n=66)$ and metastatic lymph nodes $(n=35)$, the incidences of D17S960 LOH in TP53 were increased from 19.7 to $34.8 \%$ and then $37.1 \%$, progressively $(\mathrm{P}=0.010)$. However, the incidences of D17S960 MI in TP53 in the above tissues were not different (Table II). Concerning the 66 TESCC nests, increased incidences of D17S960 LOH in TP53 were noted from T1 of 12.5, T2 of 16.7, T3 of 34.8 to T4 of $52.2 \%$, progressively $(\mathrm{P}=0.011)$ (Table II).

Among the 35 analyzed nodal positive TESCC patients, $13(13 / 35,37.1 \%)$ revealed D17S960 LOH in TP53 in the metastatic lymph nodes (nodal LOH TESCC patients, Table II). Seven $(7 / 13,53.8 \%)$ of the 13 patients with nodal $\mathrm{LOH}$ had D17S960 LOH in the paired non-cancerous esophageal mucosa, cancerous TESCC nests and metastatic lymph nodes simultaneously, and $3(3 / 7,42.9 \%)$ of the 7 exhibited a progressive allelic imbalance similarly to patient E2 (Fig. 1E). The other $6(46.2 \%)$ of the 13 patients with nodal LOH had D17S960 LOH at TP53 only in the paired cancerous TESCC nests and metastatic lymph node without non-cancerous esophageal mucosa involvement, and $3(3 / 6,50.0 \%)$ of the 6 patients displayed a progressive allelic imbalance similarly to patient F03 (Fig. 1C).

Association of microsatellite alterations in mtDNA at D310 and in TP53 at D17S960 in the 66 cancerous TESCC nests. The associations of microsatellite alterations in mtDNA at D310 and in TP53 at D17S960 among the 66 cancerous TESCC nests were compared and the correlations are shown 
Table I. Demographic data and possible prognostic variables of the 66 TESCC patients.

\begin{tabular}{cccc}
\hline Mean survival & P-value & HR & P-value \\
$(95 \% \mathrm{CI})$ months & $($ Log-rank $)$ & (95\% CI) & (Cox's regression)
\end{tabular}

Clinical variables (case number, \%)

Gender $(\mathrm{M} / \mathrm{F})$

Male $(\mathrm{n}=57,86.4 \%)$

Female $(n=9,13.6 \%)$

Cigarette smoking

Yes $(\mathrm{n}=51,77.3 \%)$

No $(n=15,22.7 \%))$

Alcohol drinking

Yes $(n=51,77.3 \%)$

No $(n=15,22.7 \%)$

Surgical-pathological status (AJCC, 7th)

T-status

$\mathrm{T} 1(\mathrm{n}=8,12.1 \%)$

$\mathrm{T} 2(\mathrm{n}=12,18.2 \%)$

T3 $(n=23,34.8 \%)$

T4 $(n=23,34.8 \%)$

$\mathrm{N}$-Status

$$
\begin{aligned}
& \text { N0 }(n=25,37.9 \%) \\
& \text { N1 }(n=23,34.8 \%) \\
& \text { N2 }(n=13,19.7 \%) \\
& \text { N3 }(n=5,7.6 \%)
\end{aligned}
$$

M-Status

M0 (n=66, 100\%)

M1 (n=0,0\%)

Stage

$$
\begin{aligned}
& \text { I }(n=9,13.6 \%) \\
& \text { II }(n=17,25.8 \%) \\
& \text { III }(n=40,60.6 \%) \\
& \text { IV }(n=0,0 \%)
\end{aligned}
$$

Molecular variables (case number, \%)

D310 mutation

Yes $(n=44,66.7 \%)$

Homoplasmic $(\mathrm{n}=17)$

Heteroplasmic $(\mathrm{n}=27)$

No $(n=22,33.3 \%)$

D17S960 allelic type

Heterozygous $(n=26,39.4 \%)$

Homozygous $(\mathrm{n}=40,60.6 \%)$

D17S960 LOH

Positive $(n=23,34.8 \%)$

Negative $(n=3,4.5 \%)$

Not informative ( $\mathrm{n}=40,60.6 \%)$

D17S960 MI

Positive $(n=6,9.1 \%)$

Negative $(n=60,90.9 \%)$
0.4378

$29.9(23.1-36.6)$

$36.3(23.4-49.2)$

$26.5(20.1-32.8)$

$44.1(30.3-57.9)$

0.1679

0.816

$27.9(21.3-34.4)$

$39.9(26.1-53.7)$

$49.0(33.5-64.4)$

0.0092

$1.524(1.046-2.222)$

1.000

0.154

36.9 (25.7-48.1)

$29.0(20.7-37.3)$

$14.5(9.3-19.6)$

$45.4(35.7-55.1)$

$27.5(19.4-35.6)$

$10.6(5.1-16.0)$

$9.7(5.9-13.5)$

$30.8(24.6-37.0)$

$55.6(42.6-68.6)$

$37.3(27.2-47.3)$

$18.6(13.7-23.4)$

$<0.001$

0.268

$<0.001 \quad 1.872(1.315-2.665)$

1.000

0.001

$0.0669 \quad 1.835(0.896-3.759)$

0.097

$26.6(19.5-33.8)$

$26.9(14.6-39.1)$

$25.2(17.6-32.8)$

37.8 (28.1-47.4)

1.000

0.2868

26.5 (17.9-35.1)

$33.1(24.9-41.3)$

0.5670

26.3 (16.6-36.0)

28.1 (24.7-31.6)

33.1 (24.9-41.3)

0.5932

24.1 (10.6-37.7)

31.3 (24.7-37.9)

0.025$$
0.268
$$ 
Table II. Microsatellite alterations in TP53 at D17S960 and in mtDNA at D310 among examined tissues.

\begin{tabular}{|c|c|c|c|c|c|}
\hline \multirow{2}{*}{$\begin{array}{l}\text { Marker } \\
\text { Types of microsatellite } \\
\text { alterations }\end{array}$} & \multicolumn{2}{|c|}{ Non-cancerous tissues } & \multicolumn{2}{|c|}{ Cancerous tissues } & \multirow[b]{2}{*}{ P-value ${ }^{a}$} \\
\hline & $\begin{array}{l}\text { Esophageal muscle } \\
\quad(n=66)(100 \%)\end{array}$ & $\begin{array}{l}\text { Esophageal mucosa } \\
\quad(n=66)(100 \%)\end{array}$ & $\begin{array}{l}\text { TESCC nests } \\
(\mathrm{n}=66)(100 \%)\end{array}$ & $\begin{array}{l}\text { Metastatic lymph nodes } \\
\qquad(\mathrm{n}=35)(100 \%)\end{array}$ & \\
\hline \multicolumn{6}{|l|}{ D17S960 (TP53) } \\
\hline $\mathrm{LOH}$ & As reference & & & & 0.010 \\
\hline Positive & & $13(19.7)$ & $23(34.8)$ & $13(37.1)$ & $0.001^{c}$ \\
\hline Negative & & $13(19.7)$ & $3(4.5)$ & $1(2.9)$ & \\
\hline Not informative & & $40(60.6)$ & $40(60.6)$ & $21(60.0)$ & \\
\hline MI & As reference & & & & 0.424 \\
\hline Positive & & $2(3.0)$ & $6(9.1)$ & $2(5.7)$ & \\
\hline Negative & & $64(90.7)$ & $60(90.9)$ & $33(94.3)$ & \\
\hline \multicolumn{6}{|l|}{ D310 (mtDNA) } \\
\hline Mutation & As reference & & & & 0.322 \\
\hline Yes & & $49(74.2)$ & $44(66.7)$ & $23(65.7)$ & \\
\hline Homoplasmic & & 7 (10.6) & $17(25.8)$ & $11(31.4)$ & $\mathbf{0 . 0 2 3}^{\mathrm{d}}$ \\
\hline Heteroplasmic & & $42(63.6)$ & $27(40.9)$ & $12(34.3)$ & \\
\hline No & & $17(25.8)$ & $22(33.3)$ & $12(34.3)$ & \\
\hline mtDNA copy ratio & $1.000 \pm 0.000$ & $0.892 \pm 0.318$ & $1.128 \pm 0.729$ & $1.183 \pm 0.591$ & $0.018^{b}$ \\
\hline
\end{tabular}

in Table III. When TESCC lesions had a TP53 MI at D17S960, they had a higher incidence of heteroplasmic mtDNA mutation at $\mathrm{D} 310(5 / 6$ vs. $22 / 60, \mathrm{P}=0.069)$ and a lower mtDNA copy ratio ( 0.68 vs. $1.17, \mathrm{P}=0.041)$. If TESCC lesions contained TP53 LOH at D17S960, they tended to have a higher mtDNA copy ratio (1.33 vs. $1.02, \mathrm{P}=0.022)$.

\section{Discussion}

We demonstrated that there was a tendency of homoplasmic mtDNA mutation at $\mathrm{D} 310(\mathrm{P}=0.023)$ and increased mtDNA copy ratios $(\mathrm{P}=0.018)$ during the progression of TESCC. Similarly, from the viewpoint of nDNA microsatellite alterations, there was also an ever increased incidence of $\mathrm{LOH}$ in TP53 at D17S960 during its progression $(\mathrm{P}=0.010$, Table II), as well as during the status from T1 to T4 TESCC lesions $(\mathrm{P}=0.011$, Table III). Such a trend of homoplasmic D310 mutation with increased mtDNA copy ratio, and a progressive allelic imbalance on nDNA at TP53 support the Nowell's cancer clonal expansion theory (33). In the literature, the notion of cancer cell clonal expansion has been extensively discussed from the viewpoint of microsatellite alterations on mtDNA at D310 in lung cancers, head and neck cancers and TESCC $(17,34,35)$ and from the view point of $\mathrm{LOH}$ on nDNA in the progression from Barrett's esophagitis to esophageal adenocarcinoma (36).

After both microsatellite alterations in mtDNA at D310 and in TP53 at D17S960 were observed in TESCC with similar trends to support the theory of cancer clonal expansion, we were prompted to investigate whether these alterations are associated. Quantitatively, we found that TP53 LOH was associated with an increase of mtDNA copy ratio $(\mathrm{P}=0.022)$ in TESCC. Qualitatively, TP53 MI was found to be highly associated with a heteroplasmic D310 mutation $(\mathrm{P}=0.069)$ in TESCC. The above findings of concomitant microsatellite alterations in mtDNA at D310 and in TP53 at D17S960 suggest that there might be a possible relationship between mitochondria and p53 in TESCC. Such an association has been reported in colon and breast cancers $(9,10)$. The association between p53 and mitochondria has been demonstrated by several recent studies, which include those supporting that p53 participates in the regulation of cellular metabolism between mitochondrial respiration and anaerobic glycolysis (37-40), in the maintenance of mtDNA integrity (41), and in the execution of the mitochondrial checkpoint (41-43). Moreover, Veatch et al (44) also proposed a retrograde signaling from mitochondrial dysfunction to nDNA LOH. However, the exact molecular mechanism has remained unclear $(6,10,45-47)$, and requires further investigation.

Although both microsatellite DNA markers, the D310 of mtDNA and D17S960 of TP53, reflected the cancer cell clonal expansion in TESCC, only the D310 mutation was found to be an independent prognostic factor in this retrospective analysis. Because of the heterozygotic nature of nDNA, only $26(39.4 \%)$ of the 66 TESCC patients harboring heterozygous alleles were informative at D17S960 and suitable for analysis of LOH (Table II). On the contrary, due to the homoplasmic nature of mtDNA in the postmitotic tissues, any alteration of the mtDNA could be easily identified. Thus, the sensitivity of D17S960 in predicting the survival of the cancer patients seemed to be 
Table III. TP53 LOH and MI with their associations to pathological status and mtDNA alterations in 66 cancerous TESCC nests.

\begin{tabular}{|c|c|c|c|c|c|c|c|}
\hline & \multicolumn{7}{|c|}{ Types of TP53 microsatellite alterations } \\
\hline & \multicolumn{3}{|c|}{$\mathrm{LOH}$} & \multirow[b]{2}{*}{ P-value ${ }^{a}$} & \multicolumn{2}{|c|}{ MI } & \multirow[b]{2}{*}{ P-value } \\
\hline & $\begin{array}{l}\text { Positive } \\
(n=23)\end{array}$ & $\begin{array}{l}\text { Negative } \\
\qquad(\mathrm{n}=3)\end{array}$ & $\begin{array}{l}\text { Not informative } \\
\qquad(\mathrm{n}=40)\end{array}$ & & $\begin{array}{l}\text { Positive } \\
(n=6)\end{array}$ & $\begin{array}{l}\text { Negative } \\
\quad(n=60)\end{array}$ & \\
\hline \multicolumn{8}{|l|}{ Pathological status (AJCC, 7th) } \\
\hline T-Status & & & & $\mathbf{0 . 0 1 1}^{\mathrm{b}}$ & & & $0.134^{\mathrm{b}}$ \\
\hline $\mathrm{T} 1(\mathrm{n}=8,100 \%)$ & $1(12.5)$ & $0(0.0)$ & $7(87.5)$ & & $2(25.0)$ & $6(75.0)$ & \\
\hline $\mathrm{T} 2(\mathrm{n}=12,100 \%)$ & $2(16.7)$ & $1(8.3)$ & $9(75.0)$ & & $0(0.0)$ & $12(100.0)$ & \\
\hline $\mathrm{T} 3(\mathrm{n}=23,100 \%)$ & $8(34.8)$ & $1(4.3)$ & $14(60.9)$ & & $4(17.4)$ & $19(82.6)$ & \\
\hline $\mathrm{T} 4(\mathrm{n}=23,100 \%)$ & $12(52.2)$ & $1(4.3)$ & $10(43.5)$ & & $0(0.0)$ & $23(100.0)$ & \\
\hline N-Status & & & & $0.535^{\mathrm{b}}$ & & & $0.410^{\mathrm{b}}$ \\
\hline N0 $(n=25,37.9 \%)$ & $7(28.0)$ & $1(4.0)$ & $17(68.0)$ & & $4(16.0)$ & $21(84.0)$ & \\
\hline $\mathrm{N} 1(\mathrm{n}=23,34.8 \%)$ & $9(39.1)$ & $2(8.7)$ & $12(52.2)$ & & $1(4.3)$ & $22(95.7)$ & \\
\hline $\mathrm{N} 2(\mathrm{n}=13,19.7 \%)$ & $5(38.5)$ & $0(0.0)$ & $8(61.5)$ & & $0(0.0)$ & $13(100.0)$ & \\
\hline $\mathrm{N} 3(\mathrm{n}=5,7.6 \%)$ & $2(40.0)$ & $0(0.0)$ & $3(60.0)$ & & $1(20.0)$ & $4(80.0)$ & \\
\hline M-Status & & & & - & & & - \\
\hline M0 $(n=66,100 \%)$ & $23(34.8)$ & $3(4.5)$ & $40(60.6)$ & & $6(9.1)$ & $60(90.9)$ & \\
\hline M1 $(n=0,0 \%)$ & - & - & - & - & - & - & - \\
\hline Stage & & & & $0.073^{\mathrm{b}}$ & & & $0.097^{\mathrm{b}}$ \\
\hline $\mathrm{I}(\mathrm{n}=9,13.6 \%)$ & $2(22.2)$ & $0(0.0)$ & $7(77.8)$ & & $2(22.2)$ & $7(77.8)$ & \\
\hline II $(\mathrm{n}=17,25.8 \%)$ & $3(17.6)$ & $2(11.8)$ & $12(70.6)$ & & $2(11.8)$ & $15(88.2)$ & \\
\hline III $(n=40,60.6 \%)$ & $18(45.0)$ & $1(2.5)$ & $21(52.5)$ & & $2(5.0)$ & $38(95.0)$ & \\
\hline IV $(n=0,0 \%)$ & - & - & - & & - & - & \\
\hline $\begin{array}{l}\text { mtDNA alterations } \\
\text { mtDNA copy ratio }(\text { mean } \pm \text { SD) }\end{array}$ & $1.33 \pm 0.73$ & $1.04 \pm 0.08$ & $1.02 \pm 0.74$ & $0.022^{c}$ & $0.68 \pm 0.57$ & $1.17 \pm 0.73$ & $0.041^{c}$ \\
\hline D310 mutation & & & & 0.423 & & & 0.069 \\
\hline Yes $(n=44,100 \%)$ & $15(34.1)$ & $1(2.3)$ & $28(63.6)$ & & $6(13.6)$ & $38(86.4)$ & \\
\hline Homoplasmic & $7(41.2)$ & $0(0.0)$ & $10(58.8)$ & & $1(5.9)$ & $16(94.1)$ & \\
\hline Heteroplasmic & $8(29.6)$ & $1(3.7)$ & $18(66.7)$ & & $5(18.5)$ & $22(81.5)$ & \\
\hline No $(n=22,100 \%)$ & $8(36.4)$ & $2(9.1)$ & $12(54.5)$ & & $0(0.0)$ & $22(100.0)$ & \\
\hline
\end{tabular}

AJCC, American Joint Committee on Cancer; LOH, loss of heterozygosity; SD, standard deviation; ${ }^{\mathrm{a}} \chi^{2}$ test; ${ }^{\mathrm{b}} \chi^{2}$ test for trend; ${ }^{\mathrm{c}} \mathrm{ANOVA} /$ Kruskall-Wallis $\mathrm{H}$ test or t-test/Mann-Whitney U test. Bold indicates statistically significant differences.

attenuated. This may account for the higher sensitivity of the D310 mutation of mtDNA in the prognosis of TESCC (17).

In conclusion, we demonstrated that both microsatellite alterations in mtDNA at D310 and in TP53 at D17S960 are good DNA markers to support the clonal expansion theory in TESCC cancer. Associated microsatellite alterations on TP53 and on mtDNA in analyzed TESCC samples suggest a possible relationship between the mitochondria and p53 in TESCC. However, further investigation is warranted to understand the molecular basis of this association.

\section{Acknowledgements}

This study was supported by grants from the North Region Alliance of the Department of Health Hospitals of Taiwan (no. 97-04, no. 98-09 and no. 99-05 for Keelung Hospital and Taipei Hospital), a collaborative research grant from the
Changhua Christian Hospital (97-CCH-YMU-01) and a grant (NSC97-2320-B-010-013-MY3) from the National Science Council, Executive Yuan, Taiwan.

\section{References}

1. Hsu CP, Chen CY, Hsia JY and Shai SE: Prediction of prognosis by the extent of lymph node involvement in squamous cell carcinoma of the thoracic esophagus. Eur J Cardiothorac Surg 19: 10-13, 2001.

2. Lin CS, Chang SC, Wei YH, et al: Prognostic variables in thoracic esophageal squamous cell carcinoma. Ann Thorac Surg 87: 1056-1065, 2009.

3. Wang HW, Chu PY, Kuo KT, et al: A reappraisal of surgical management for squamous cell carcinoma in the pharyngoesophageal junction. J Surg Oncol 93: 468-476, 2006.

4. Wang LS, Chow KC, Chi KH, et al: Prognosis of esophageal squamous cell carcinoma: analysis of clinicopathological and biological factors. Am J Gastroenterol 94: 1933-1940, 1999. 
5. Wang LS, Chow KC, Lien YC, Kuo KT and Li WY: Prognostic significance of nm23-H1 expression in esophageal squamous cell carcinoma. Eur J Cardiothorac Surg 26: 419-424, 2004.

6. Hibi K, Nakayama H, Yamazaki T, et al: Mitochondrial DNA alteration in esophageal cancer. Int J Cancer 92: 319-321, 2001.

7. Shi ST, Yang GY, Wang LD, et al: Role of p53 gene mutations in human esophageal carcinogenesis: results from immunohistochemical and mutation analyses of carcinomas and nearby non-cancerous lesions. Carcinogenesis 20: 591-597, 1999.

8. Wang LS, Chow KC, Liu CC and Chiu JH: p53 gene alternation in squamous cell carcinoma of the esophagus detected by PCR-cold SSCP analysis. Proc Natl Sci Counc Repub China B 22: 114-121, 1998.

9. Chang SC, Lin PC, Yang SH, Wang HS, Liang WY and Lin JK: Mitochondrial D-loop mutation is a common event in colorectal cancers with p53 mutations. Int J Colorectal Dis 24: 623-628, 2009.

10. Gochhait S, Bhatt A, Sharma S, Singh YP, Gupta P and Bamezai RN: Concomitant presence of mutations in mitochondrial genome and p53 in cancer development: a study in north Indian sporadic breast and esophageal cancer patients. Int J Cancer 123: 2580-2586, 2008.

11. Lee HC and Wei YH: Mitochondrial role in life and death of the cell. J Biomed Sci 7: 2-15, 2000.

12. Lee HC and Wei YH: Mitochondrial biogenesis and mitochondrial DNA maintenance of mammalian cells under oxidative stress. Int J Biochem Cell Biol 37: 822-834, 2005.

13. Eckert KA and Hile SE: Every microsatellite is different: intrinsic DNA features dictate mutagenesis of common microsatellites present in the human genome. Mol Carcinog 48 379-388, 2009.

14. Cai YC, So CK, Nie AY, et al: Characterization of genetic alteration patterns in human esophageal squamous cell carcinoma using selected microsatellite markers spanning multiple loci. Int J Oncol 30: 1059-1067, 2007

15. Fujiki T, Haraoka S, Yoshioka S, Ohshima K, Iwashita A and Kikuchi M: p53 gene mutation and genetic instability in superficial multifocal esophageal squamous cell carcinoma. Int J Oncol 20: 669-679, 2002

16. Matsumoto T, Fujii H, Arakawa A, et al: Loss of heterozygosity analysis shows monoclonal evolution with frequent genetic progression and divergence in esophageal carcinosarcoma. Hum Pathol 35: 322-327, 2004.

17. Lin CS, Chang SC, Wang LS, et al: The role of mitochondrial DNA alterations in esophageal squamous cell carcinomas. J Thorac Cardiovasc Surg 139: 189-197, 2010.

18. Lee HC, Yin PH, Lin JC, et al: Mitochondrial genome instability and mtDNA depletion in human cancers. Ann NY Acad Sci 1042: 109-122, 2005.

19. Tseng LM, Yin PH, Chi CW, et al: Mitochondrial DNA mutations and mitochondrial DNA depletion in breast cancer. Genes Chromosomes Cancer 45: 629-638, 2006.

20. Wu CW, Yin PH, Hung WY, et al: Mitochondrial DNA mutations and mitochondrial DNA depletion in gastric cancer. Genes Chromosomes Cancer 44: 19-28, 2005.

21. Lin CS, Wang LS, Tsai CM and Wei YH: Low copy number and low oxidative damage of mitochondrial DNA are associated with tumor progression in lung cancer tissues after neoadjuvant chemotherapy. Interact Cardiovasc Thorac Surg 7: 954-958, 2008.

22. Bai RK, Perng CL, Hsu CH and Wong LJ: Quantitative PCR analysis of mitochondrial DNA content in patients with mitochondrial disease. Ann N Y Acad Sci 1011: 304-309, 2004.

23. Lee HC, Hsu LS, Yin PH, Lee LM and Chi CW: Heteroplasmic mutation of mitochondrial DNA D-loop and 4977-bp deletion in human cancer cells during mitochondrial DNA depletion. Mitochondrion 7: 157-163, 2007.

24. Weissenbach J, Gyapay G, Dib C, et al: A second-generation linkage map of the human genome. Nature 359: 794-801, 1992

25. Albertoni M, Daub DM, Arden KC, Viars CS, Powell C and Van Meir EG: Genetic instability leads to loss of both p53 alleles in a human glioblastoma. Oncogene 16: 321-326, 1998.
26. Edwards J, Duncan P, Going JJ, Grigor KM, Watters AD and Bartlett JM: Loss of heterozygosity on chromosomes 11 and 17 are markers of recurrence in TCC of the bladder. Br J Cancer 85 : 1894-1899, 2001

27. Soon PS, Libe R, Benn DE, et al: Loss of heterozygosity of $17 \mathrm{p} 13$, with possible involvement of ACADVL and ALOX15B, in the pathogenesis of adrenocortical tumors. Ann Surg 247: 157-164, 2008.

28. Yoshimura A, Sugihara H, Ling ZQ, et al: How wild-type TP53 is inactivated in undifferentiated-type gastric carcinomas: analyses of intratumoral heterogeneity in deletion and mutation of TP53. Pathobiology 73: 40-49, 2006.

29. Eisenberger CF, Schoenberg M, Enger C, et al: Diagnosis of renal cancer by molecular urinalysis. J Natl Cancer Inst 91: 2028-2032, 1999.

30. Niederacher D, Picard F, van Roeyen C, An HX, Bender HG and Beckmann MW: Patterns of allelic loss on chromosome 17 in sporadic breast carcinomas detected by fluorescent-labeled microsatellite analysis. Genes Chromosomes Cancer 18: 181-192, 1997.

31. Wong KK, Tsang YT, Shen J, et al: Allelic imbalance analysis by high-density single-nucleotide polymorphic allele (SNP) array with whole genome amplified DNA. Nucleic Acids Res 32: e69, 2004.

32. Rice TW, Blackstone EH and Rusch VW: 7th edition of the AJCC Cancer Staging Manual: esophagus and esophagogastric junction. Ann Surg Oncol 17: 1721-1724, 2010.

33. Nowell PC: The clonal evolution of tumor cell populations. Science 194: 23-28, 1976

34. Ha PK, Tong BC, Westra WH, et al: Mitochondrial C-tract alteration in premalignant lesions of the head and neck: a marker for progression and clonal proliferation. Clin Cancer Res 8: 2260-2265, 2002.

35. Sanchez-Cespedes M, Parrella P, Nomoto S, et al: Identification of a mononucleotide repeat as a major target for mitochondrial DNA alterations in human tumors. Cancer Res 61: 7015-7019, 2001.

36. Maley CC and Reid BJ: Natural selection in neoplastic progression of Barrett's esophagus. Semin Cancer Biol 15: 474-483, 2005.

37. Bensaad K, Tsuruta A, Selak MA, et al: TIGAR, a p53-inducible regulator of glycolysis and apoptosis. Cell 126: 107-120, 2006.

38. Bensaad $\mathrm{K}$ and Vousden $\mathrm{KH}$ : p53: new roles in metabolism. Trends Cell Biol 17: 286-291, 2007.

39. Kondoh H, Lleonart ME, Gil J, et al: Glycolytic enzymes can modulate cellular life span. Cancer Res 65: 177-185, 2005.

40. Matoba S, Kang JG, Patino WD, et al: p53 regulates mitochondrial respiration. Science 312: 1650-1653, 2006.

41. Kulawiec M, Ayyasamy V and Singh KK: p53 regulates mtDNA copy number and mitocheckpoint pathway. J Carcinog 8: 8, 2009.

42. Lebedeva MA, Eaton JS and Shadel GS: Loss of p53 causes mitochondrial DNA depletion and altered mitochondrial reactive oxygen species homeostasis. Biochim Biophys Acta 1787: 328-334, 2009.

43. Saleem A, Adhihetty PJ and Hood DA: Role of p53 in mitochondrial biogenesis and apoptosis in skeletal muscle. Physiol Genomics 37: 58-66, 2009.

44. Veatch JR, McMurray MA, Nelson ZW and Gottschling DE: Mitochondrial dysfunction leads to nuclear genome instability via an iron-sulfur cluster defect. Cell 137: 1247-1258, 2009.

45. Bianchi NO, Bianchi MS and Richard SM: Mitochondrial genome instability in human cancers. Mutat Res 488: 9-23, 2001.

46. Habano W, Sugai T, Nakamura SI, Uesugi N, Yoshida T and Sasou S: Microsatellite instability and mutation of mitochondrial and nuclear DNA in gastric carcinoma. Gastroenterology 118: $835-841,2000$

47. Hiyama T, Tanaka S, Shima H, et al: Somatic mutation in mitochondrial DNA and nuclear microsatellite instability in gastric cancer. Oncol Rep 10: 1837-1841, 2003. 